\title{
Quantifying the Relationship between Phases of Stem Elongation and Flower Initiation in Poinsettia
}

\author{
Paul R. Fisher ${ }^{1}$ and Royal D. Heins \\ Department of Horticulture, Michigan State University, East Lansing, MI 48824-1325 \\ J. Heinrich Lieth \\ Department of Environmental Horticulture, University of California, Davis, CA 95616-8587
}

\begin{abstract}
Additional index words. Euphorbia pulcherrima, plant growth, height control, Richards function, simulation, graphical tracking

Abstract. Stem elongation of poinsettia (Euphorbia pulcherrima Klotz.) was quantified using an approach that explicitly modelled the three phases of a sigmoidal growth curve: 1) an initial lag phase characterized by an exponentially increasing stem length, 2) a phase in which elongation is nearly linear, and 3) a plateau phase in which elongation rate declines as stem length reaches an asymptotic maximum. For each growth phase, suitable mathematical functions were selected for smooth height and slope transitions between phases. The three growth phases were linked to developmental events, particularly flower initiation and the first observation of a visible flower bud. The model was fit to a data set of single-stemmed poinsettia grown with vegetative periods of 13,26 , or 54 days, resulting in excellent conformance $\left(R^{2}=0.99\right)$. The model was validated against two independent data sets, and the elongation pattern was similar to that predicted by the model, particularly during the linear and plateau phases. The model was formulated to allow dynamic simulation or adaptation in a graphical control chart. Model parameters in the three-phase function have clear biological meaning. The function is particularly suited to situations in which identification of growth phases in relation to developmental and horticultural variables is an important objective. Further validation under a range of conditions is required before the model can be applied to horticultural situations.
\end{abstract}

Under constant environmental conditions, shoot elongation of determinate plants usually follows a sigmoidal pattern. In general, such patterns consist of three phases (Richards, 1969). The first phase, an initial lag phase, is characterized by a period of increasing growth rate during which cells remain meristematic and continue to divide at approximately equal intervals. In the second period, elongation is approximately linear. Finally, through limiting resources or maturation, there is a plateau phase in which the elongation rate declines until the length reaches an asymptotic maximum. Various models have been proposed for this pattern, with the Richards function (Richards, 1959,1969) being one of the most widely used. These models generally include only an implicit reference to events such as the points of transition between the phases or development of the plant, making their use in a horticultural setting difficult, if not impossible.

The goal was to quantify stem elongation of single-stem poinsettia (Euphorbia pulcherrima) using a modelling approach that included parameters or variables explicitly referencing developmental and horticultural events, as well as the growth-phase transition points to which they are linked. The phasic model was intended for use as a dynamic graphical control tool for height control and scheduling of poinsettia, where the elongation curve is used as a guideline against which actual plant height is compared. Such a model is useful for simulating and predicting short-term elongation rates, a necessary component for poinsettia height control in a decision-support system that we are developing (Fisher and Heins, 1995). Simulation requires that the mathematical model be represented as a differential equation that then can be solved numerically over any desired period. Although the Richards

Received for publication 16 June 1995. Accepted for publication 4 Dec. 1995. The cost of publishing this paper was defrayed in part by the payment of page charges. Under postal regulations, this paper therefore must be hereby marked advertisement solely to indicate this fact.

${ }^{1}$ Current address: Dept. of Environmental Horticulture, Univ. of California, Davis, CA $95616-8587$. function can be used for simulation, any changes in environmental conditions would force the entire elongation trajectory to change (even for the growth phases that had already occurred). It would be desirable to incorporate transition points explicitly as parameters in a sigmoid function for situations in which phase duration may vary, as is the case for greenhouse crops such as poinsettia.

Poinsettias are greenhouse-grown under exacting horticultural conditions and practices to produce crops of uniform size and quality on a precise schedule. The final products (ranging from small plants to trees) require variations in cultural protocol. In particular, many plants are pinched (pinching refers to the removal of the apical meristem), while others are not pinched to produce a single shoot. In this report we deal only with poinsettia plants that are grown from rooted cuttings without being pinched during production.

In horticultural production, poinsettia plants are forced to go through specific vegetative and reproductive developmental phases that are coupled to the growth phases. During the vegetative period, night lengths are kept short so that only leaf primordia are initiated. The beginning of a period in which night lengths are maintained longer than $11.75 \mathrm{~h}$ (Larson and Langhans, 1963) is referred to as the flower initiation date or short-day date. The resulting formation of flower-bud primordia on the apical meristem means that no further nodal leaf primordia are developed. Thus, manipulation of the short-day date affects all aspects of reproductive development and various components of growth. The observable characteristics of the plant that are affected, and therefore suitable for quantifying progress of the crop, are leaf number, internode count and length, and stem length (plant height) (Berghage and Heins, 1991). We tracked each of these variables and sought to develop a mathematical stem-length model suitable for maintaining precise control of the production process.

Models for shoot elongation have been developed for greenhouse crops including chrysanthemum (Karlsson and Heins, 1994; Larsen and Lieth, 1993) and Easter lily (Lieth and Carpenter, 1990). For these objectives the Richards function was adequate. 
(a)

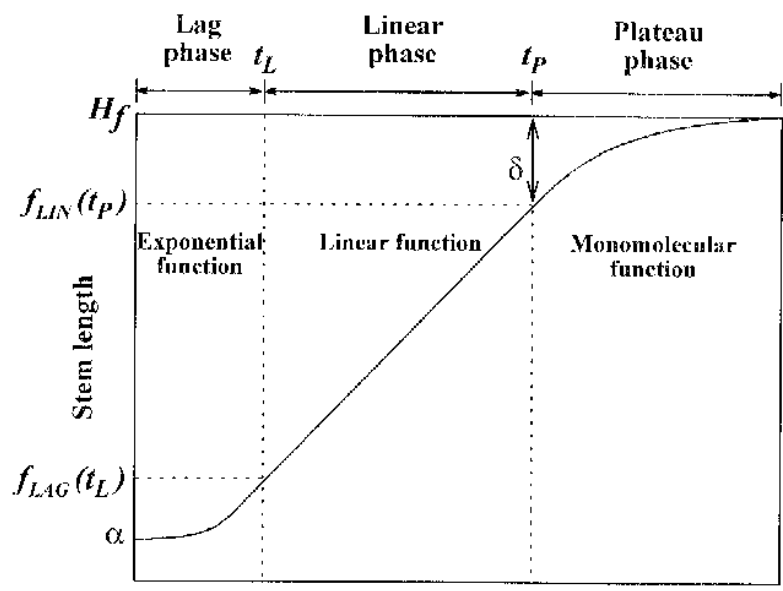

(b)

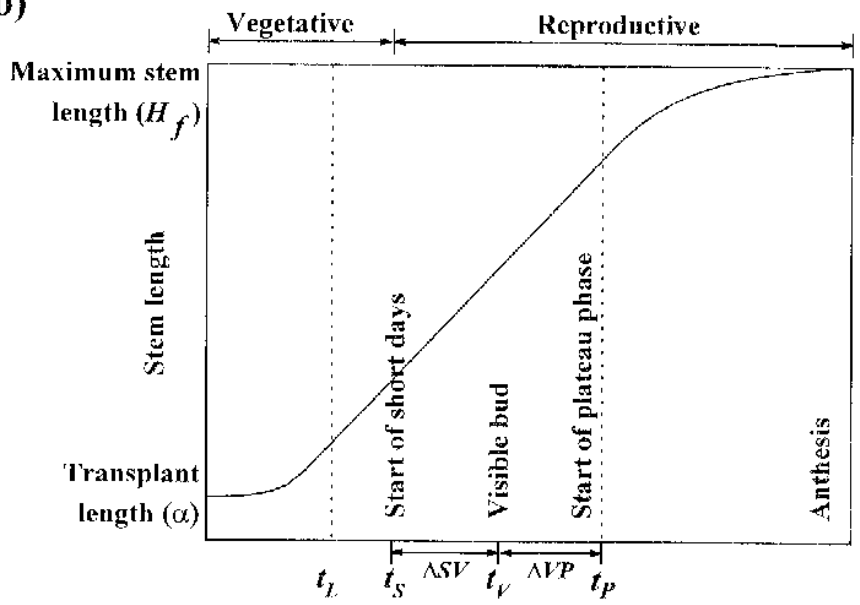

Days after transplant

Fig. 1. (a) Components of the $f_{3-p h a s e}$ function stem-length curve. (b) Modification of the $f_{3-\text { phase }}$ function for poinsettia to estimate $t_{P}$ based on timing of short days $\left(t_{S}\right)$ and visible bud $\left(t_{V}\right)$.
However, in process control of the height of potted plants, slight biases in the model predictions, even over short periods, may result in plants that do not meet consumers' aesthetic requirements or fit into the shipping container. Thus, a model was needed that would provide a close fit to observed data while providing linkages to the actual horticultural variables used in ornamental production.

Our objective was to quantify elongation of single-stemmed poinsettia, using a mathematical model in which each of the three phases of elongation (lag, linear, and plateau) was quantified explicitly. The model had to be differentiable so that the resulting rate equations would allow dynamic simulation within a decisionsupport system. The model was calibrated against a data set of single-stemmed poinsettia grown over a range of flower initiation dates and linked to other measurable variables. A limited validation was performed against two independent data sets of plants grown in similar greenhouse conditions.

\section{Materials and Methods}

Model theory. Mathematical functions were selected for each of the sigmoidal phases of stem elongation (Fig. 1a), resulting in a three-phase $\left(f_{3-\text { phase }}\right)$ model explicitly representing an initial lag phase, a linear phase, and a plateau phase. The transition points between the three phases were denoted $t_{L}$ and $t_{p}$, respectively. During each phase of elongation, stem length was described with a separate function (denoted $f_{L A G}(t), f_{L I N}(t)$, and $f_{P L A}(t)$, respectively). These were set up so that the first derivatives $\left(f_{\text {LAG }}(t)\right.$, $f^{\prime}{ }_{L I}(t)$, and $f_{P L A}^{\prime}(t)$, respectively) were continuous at $t_{L}$ and $t_{P}$, mathematically expressed as

$$
f_{3-\text { phase }}(t)=\begin{array}{ll}
f_{\mathrm{LAG}}(t) & \text {...for } t \leq t_{\mathrm{L}} \\
f_{\mathrm{LIN}}(t) & \text {..for } t_{\mathrm{L}}<t \leq t_{\mathrm{P}} \\
f_{\mathrm{PLA}}(t) & \text {...for } t>t_{\mathrm{P}}
\end{array}
$$

where

Table 1. List of variables, parameters, and abbreviations.

\begin{tabular}{llc}
\hline \hline Symbol & \multicolumn{1}{c}{ Description } & Unit \\
\hline$\alpha$ & Initial stem length in lag phase of $f_{3-p h a s e}$ & mm \\
$\beta$ & Rate parameter in lag phase & per day \\
$\beta_{13}, \beta_{26}, \beta_{54}$ & Rate parameter for the lag phase of the S13, S26, and S54 & per day \\
$\gamma$ & treatments, respectively & $\mathrm{mm}^{-1}$ \\
$\delta$ & Gradient of linear phase & mm \\
$\Delta t_{S V}$ & Asymptotic potential growth during plateau phase $\left(t_{V}\right)$ & days \\
$\Delta t_{V P}$ & Time from the short-day date $\left(t_{S}\right)$ to visible bud day & days \\
$f_{3-p h a s e}$ & Days from visible bud day $\left(t_{V}\right)$ to $t_{P}$ & --- \\
$f_{L A G}$ & Three-phase stem-elongation model for stem length & --- \\
$f_{L I N}$ & Function for the lag phase & --- \\
$f_{P L A}$ & Function for the linear phase & --- \\
$H_{f}$ & Function for the plateau phase & mm \\
$k$ & Final stem length & per day \\
S13, S26, S54 & Rate parameter in plateau phase & -- \\
& Experimental treatment, short days beginning 13, 26, and 54 days & days \\
$t$ & after transplant, respectively & days \\
$t_{L}$ & Time variable & days \\
$t_{P}$ & Time when lag phase ends and linear phase begins & days \\
$t_{S}$ & Time when linear phase ends and plateau phase begins & days \\
$t_{V}$ & Days after transplant at which short (flower-initiating) & \\
\hline & photoperiods begin & \\
& Days after transplant at which visible bud occurs &
\end{tabular}


$f_{\mathrm{LAG}}\left(t_{\mathrm{L}}\right)=f_{\mathrm{LIN}}\left(t_{\mathrm{L}}\right)$

$f_{\text {LIN }}\left(t_{\mathrm{P}}\right)=f_{\mathrm{PLA}}\left(t_{\mathrm{P}}\right)$

$f_{\text {LAG }}^{\prime \prime}\left(t_{\mathrm{L}}\right)=f_{\text {LIN }}^{\prime}\left(t_{\mathrm{L}}\right)$

$f_{\text {LIN }}^{\text {LAd }}\left(t_{\mathrm{P}}\right)=f_{\text {PLA }}^{\prime \text { LIN }}\left(t_{\mathrm{P}}\right)$

See Table 1 for a summary of variables, parameters, and abbreviations.

Mathematical functions that provided the empirical qualities desired for each phase were chosen. Increasing growth rate during the lag phase was described with an exponential function in which $\alpha$ was the initial value and $\beta$ was a rate constant. Constant growth rate during the linear phase was described with a linear function with elongation rate $\gamma$. A monomolecular function in which the quantity of growth remaining when the plateau phase began was represented by $\delta$, and $k$ represented the rate at which the crop reached the asymptote during the plateau. Thus, Eq. [1] becomes

$$
f_{3-\text { phase }}(t)=\begin{array}{ll}
\alpha+e^{\beta t}-1 & \text {..for } t \leq t_{\mathrm{L}} \\
f_{\mathrm{LAG}}\left(t_{\mathrm{L}}\right)+\gamma t & \ldots \text { for } t_{\mathrm{L}}<t \leq t_{\mathrm{P}} \\
f_{\mathrm{LIN}}\left(t_{\mathrm{P}}\right)+\delta\left(1-e^{-k\left(t-t_{\mathrm{P}}\right)}\right. & \ldots \text { for } t>t_{\mathrm{P}}
\end{array}
$$

with a first derivative of

$$
f_{3-\text { phase }} \quad(t)=\begin{array}{ll}
\beta e^{\beta t} & \text {..for } t \leq t_{\mathrm{L}} \\
\gamma \delta \delta e^{-k\left(t-\mathrm{t}_{\mathrm{p}}\right)} & \text {...for } t_{\mathrm{L}}<t \leq t_{\mathrm{P}} \\
& \text {..for } t>t_{\mathrm{P}}
\end{array}
$$

Requiring that $f_{L A G}$ and $f_{L I N}$ have equal first derivatives at $t_{L}$ means

$$
\gamma=\beta e_{\mathrm{L}}^{\beta t}
$$

or, if $\gamma$ is given, that

$$
t_{\mathrm{L}}=\ln (\gamma)-\ln (\beta) / \beta
$$

Equal first derivatives of $f_{L I N}$ and $f_{P L A}$ at $t_{P}$ mean that

$$
\gamma=k \delta e^{-\mathrm{k}\left(t_{\mathrm{P}}-t_{\mathrm{P}}\right)}=k \delta
$$

or, if $\gamma$ is given, that $k$ can be calculated as

$$
k=\gamma / \delta
$$

Model application to poinsettia stem elongation. For poinsettia there are several developmental and horticultural events related to these phases (Fig 1b). The short-day date $\left(t_{s}\right)$ occurs when night lengths facilitate reproductive development. The visible-bud day $\left(t_{V}\right)$ occurs when at least one complete flower bud is visible without moving leaves. The final presale event is anthesis, defined as the first day that anthers are visible on at least one cyathium. Durations of stages between $t_{S}$ and $t_{V}$ and $t_{V}$ and $t_{P}$ are denoted as $\Delta t_{S V}$ and $\Delta t_{V P}$, respectively:

$$
t_{\mathrm{P}}=t_{\mathrm{S}}+\Delta t_{\mathrm{SV}}+\Delta t_{\mathrm{VP}}
$$

Based on Berghage and Heins' (1991) results, we hypothesized that the primary effect of delaying $t_{s}$ was to delay the start of the plateau phase by the same amount of time. Thus, we assumed that $\Delta t_{S V}$ and $\Delta t_{V P}$ were constants at one average temperature and for one cultivar. By using the relationships in Eqs. [6] and [8] and replacing $t_{P}$ with $t_{V}+\Delta t_{V P}$, the model for stem elongation has five parameters, $\alpha, \beta, \gamma, \Delta t_{V P}$, and $\delta$ estimated, and input variables $t_{S}$ and $\Delta t_{S V^{*}}$
Experimental design for poinsettia. Unpinched (i.e., singlestemmed) 'Freedom' poinsettia plants were grown during 1994 in a Michigan State Univ., East Lansing, greenhouse. Rooted cuttings were obtained from Paul Ecke Poinsettia Ranch (Encinitas, Calif.) on three dates so that varying lengths of the vegetative period could culminate on the same short-day date. The cuttings of each of these batches of 10 plants had eight to 10 leaves and were planted into $15-\mathrm{cm}$-diameter $\left(1000-\mathrm{cm}^{3}\right)$ pots with Metro Mix 510 medium (Scotts, Marysville, Ohio) on 4 Aug., 1 Sept., and 14 Sept., respectively. Plants were placed at $35 \times 35 \mathrm{~cm}$ to avoid interplant shading. Four-hour night-interruption lighting from 2200 to 0200 HR was provided for all plants until 27 Sept. The plants from each of the three planting-date treatments were placed under shadecloth to provide a night length of $15 \mathrm{~h}$ throughout the remainder of the experiment. Thus, the groups planted on 4 Aug., 1 Sept., and 14 Sept. had $t_{S}$ of 54, 26, and 13 days, respectively, and were denoted as treatments 'S54', 'S26', and 'S13', respectively. Stem length from the pot rim upward and leaf number were recorded twice weekly for each of five randomly selected plants

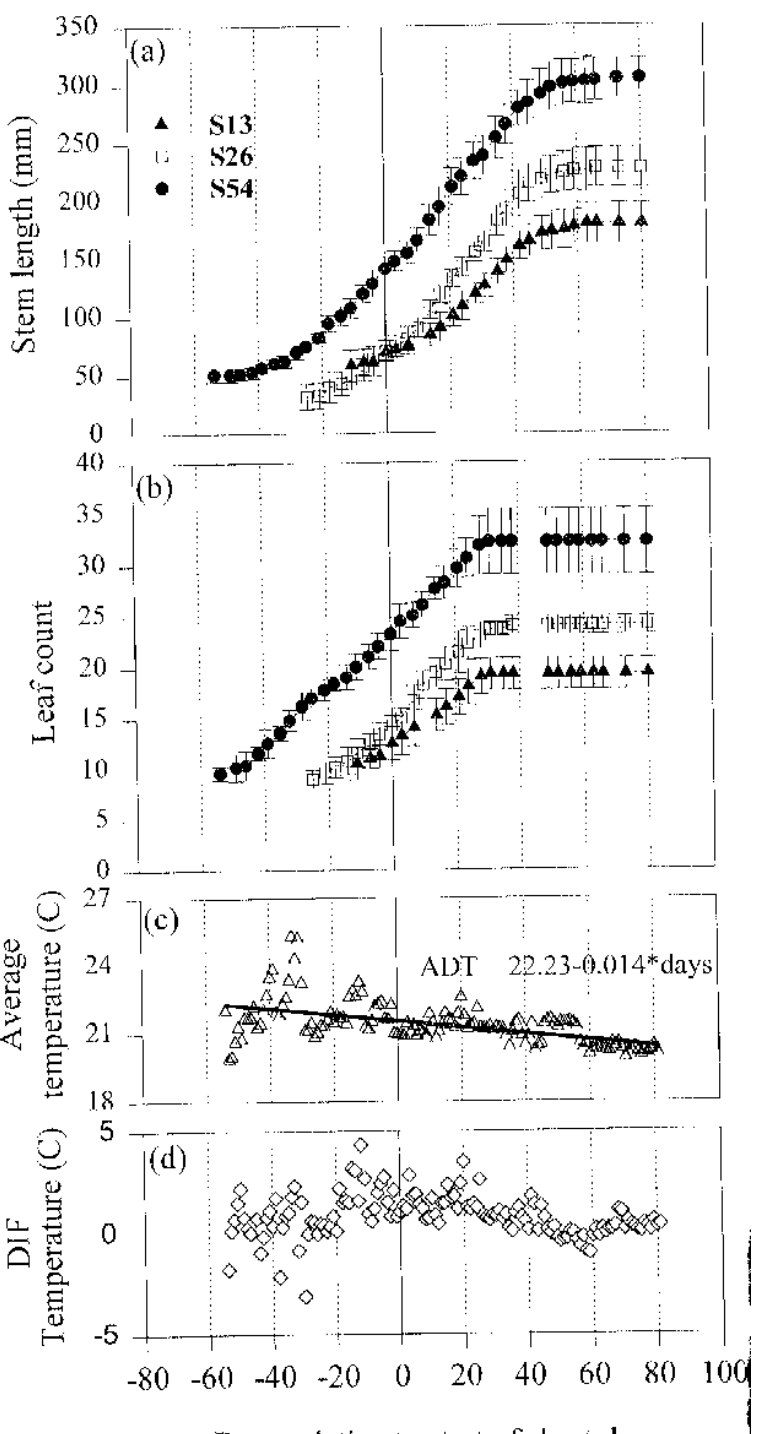

Days relative to start of short days

Fig. 2. (a) Mean stem length and (b) leaf count over time for the three short-day treatments (mean of five plants $\pm 95 \%$ confidence intervals); $\boldsymbol{\Delta}=\mathrm{S} 13, \square=\mathrm{S} 26$, $\boldsymbol{0}=\mathrm{S} 54$ ). (c) $\Delta=$ average temperature and (d) $\diamond=\operatorname{DIF}$ (average day minus average night) temperatures during the experimental period. 
Table 2. Phenological and growth data (mean $\pm 95 \%$ confidence intervals) for each photoperiod treatment.

\begin{tabular}{lcccc}
\hline \hline & \multicolumn{3}{c}{ Photoperiod treatment } & S54 \\
\cline { 2 - 4 } Parameter & $\mathrm{S} 13$ & $\mathrm{~S} 26$ & $72.4 \pm 4.9$ & Significance \\
\hline Number of days from planting to $t_{V}$ & $33.4 \pm 1.3$ & $46.6 \pm 4.3$ & $23.4 \pm 4.9$ & NS \\
Days from $t_{S}$ to $t_{V}$ & $25.4 \pm 1.3$ & $23.6 \pm 4.3$ & $105.8 \pm 1.1$ & $* * *$ \\
Days from planting to anthesis & $68.4 \pm 7.1$ & $81.4 \pm 7.2$ & $51.8 \pm 1.1$ & NS \\
Days from $t_{S}$ to anthesis & $55.4 \pm 7.1$ & $55.4 \pm 7.2$ & $51 \pm 6$ & $* *$ \\
Initial stem length (mm) & $56 \pm 14$ & $22 \pm \pm 25$ & $303 \pm 21$ & $* * *$ \\
Final stem length (mm) & $180 \pm 26$ & $24 \pm 1.0$ & $32.2 \pm 3.6$ & $* * *$ \\
Final internode number & $19.4 \pm 1.5$ & & & \\
\hline
\end{tabular}

$\overline{\mathrm{Ns}, * *, * * *}$ Nonsignificant or significant at $P=0.01$ or 0.001 , respectively.

from each treatment group. The plants were checked three times weekly for visible bud or anthesis. At the end of the experiment, leaf count (in which a leaf was counted when the midrib was completely visible), internode lengths, and stem length were measured. Two-hour average air temperature was logged with an aspirated thermocouple with the air intake at the plant canopy height. Day and night temperature settings were a constant $21^{\circ} \mathrm{C}$, and actual temperatures were an average daily temperature of 21.4 $\pm 0.2{ }^{\circ} \mathrm{C}$ (means are presented with $\pm 95 \%$ confidence intervals unless otherwise stated) with a DIF temperature (average day minus average night) of $0.8^{\circ} \mathrm{C}$.

Validation experiments. Two validation experiments were run, each with five rooted cuttings of 'Freedom' poinsettia grown as single-stemmed plants in a Michigan State University greenhouse. During both 1992 and 1993, rooted cuttings were transplanted into $15-\mathrm{cm}$-diameter $\left(1000-\mathrm{cm}^{3}\right)$ pots on $20 \mathrm{Aug}$. Plants were placed at $30 \times 30$ - $\mathrm{cm}$ spacing and were surrounded by unmeasured boundary plants. In 1992, plants were grown under natural photoperiods throughout the experiment with temperature settings at a constant $20^{\circ} \mathrm{C}$ (actual average daily temperature was $20.1 \pm 0.4^{\circ} \mathrm{C}$ and DIF was $\left.0.4 \pm 0.4^{\circ} \mathrm{C}\right)$. During 1993, plants were grown at a constant 21 ${ }^{\circ} \mathrm{C}$ setting (actual average $21.5 \pm 0.4{ }^{\circ} \mathrm{C}$, DIF $-0.2 \pm 0.4{ }^{\circ} \mathrm{C}$ ) with four-hour night interruption lighting until 25 Sept., when black cloth was pulled to provide a night length of $15 \mathrm{~h}$ until 25 Oct., after which the crop was grown under natural photoperiods. Plant height was recorded twice per week, and plants were checked three times per week for visible bud.

Analysis. All model fittings to the height data were done using SAS's nonlinear regression procedure (PROC NLIN) (SAS Institute, 1988). First, $f_{3-\text { phase }}$ was fit separately to observed data from each photoperiod treatment (i.e., three groups of cuttings), and the resulting parameter estimates were inspected for trends. The model then was fit to the entire data set in one combined analysis (the all-treatments model) by fixing known constants and incorporating the effect of the short-day treatments directly in the model. Thus, $\alpha$ was assigned the value of the observed stem length at transplanting. Each short-day treatment was assigned a separate $\beta$ parameter to quantify elongation during the lag phase $\left(\beta_{13}, \beta_{26}\right.$, and $\beta_{54}$ for the S13, S26, and S54 treatments, respectively). The remaining parameters, $\gamma, \Delta t_{V P}$, and $\delta$, were assumed independent of treatment. Results of the fittings compared with the actual data.

The model was then used to predict plant heights for the two validation experiments. a was assigned the value of the observed stem length at transplanting, and estimates of $\gamma, \Delta t_{V P}$, and $\mathrm{d}$ from the calibration experiment all-treatments model were used. $\beta$ was varied between the minimum and maximum value of $\beta_{13}, \beta_{26}$, and $\beta_{54}$ in the all-treatments model to provide a range in predicted values. For the 1992 experiment, the observed $t_{V}$ was used to predict timing of $t_{P}$ (where $t_{P}$ equals $t_{V}+\Delta t_{V P}$ ) because plants were grown under natural photoperiods and $t_{S}$ was unknown. In the 1993 experiment, $t_{S}$ occurred 36 days after transplanting, and Eq. [9] was used to predict $t_{p}$. The predicted range in plant heights was then compared graphically against data from the validation experiments.

\section{Results}

Stem length of the three short-day treatments followed a sigmoidal pattern over time (Fig. 2a). The average time between $t_{S}$ and $t_{V}\left(\Delta t_{S V}\right)$ for plants in the three treatments was $24.1 \pm 1.6$ days; from $t_{S}$ to anthesis took $54.2 \pm 2.5$ days. Neither interval length was significantly different among the treatments. The parameter $\Delta t_{S V}$ was therefore assigned a constant value of 24.1 days for all treatments. Elongation after anthesis was $<10 \mathrm{~mm}$ among the three treatments.

The longer the period between transplant and $t_{s}$, the longer the final stem length. The difference in final stem length primarily was caused by an increase in internode (leaf) number because of differences in length of the vegetative period (Table 2, Fig. 2b). There was no significant difference in the initial number of leaves, with an average 9.6 \pm 0.5 leaves at planting. After an initial lag, leaf unfolding rate was nearly linear until $t_{V}$, after which up to four more leaves unfolded on the main stem. The S26 treatment's leaves unfolded more rapidly than those of the other treatments. Final length of internodes one to eight (counting upward) decreased (Fig. 3), and these nodes were expanding at the time cuttings from stock plants were being rooted (i.e., before the experiment started). Internodes nine to 14 expanded after planting and during the lag

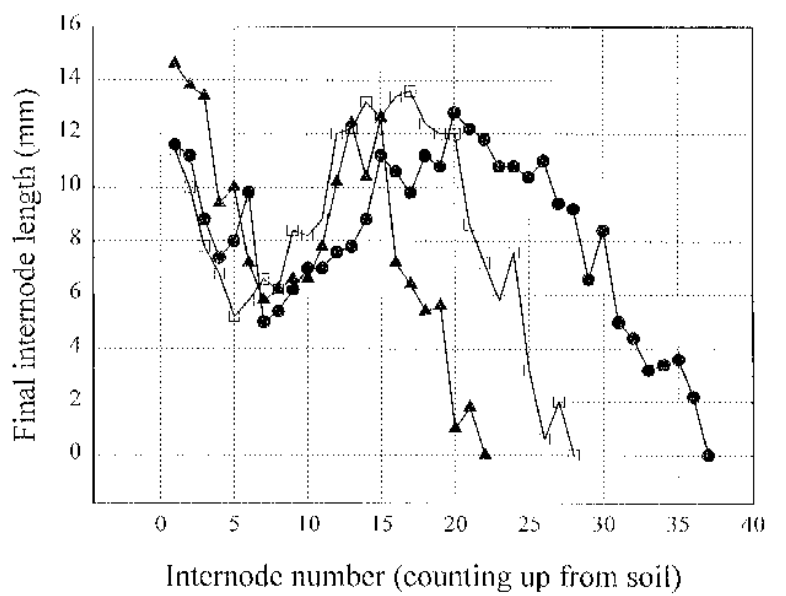

Fig. 3. Final internode lengths (mean of five plants) for the short-day treatments ( $=\mathrm{S} 13, \square=\mathrm{S} 26, \mathbf{O}=\mathrm{S} 54$ ). 

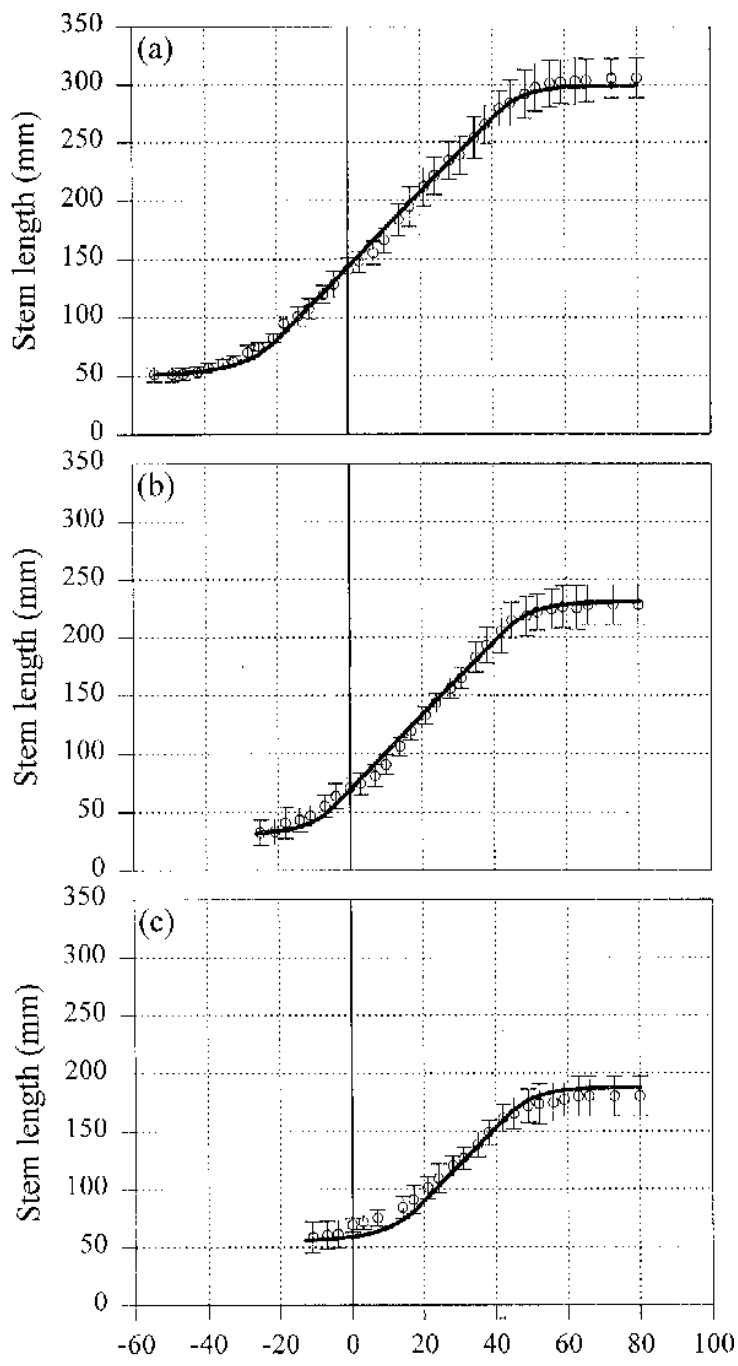

Days relative to the start of short days

Fig. 4. Fit of $f_{\text {3-phase }}$ function (solid line) to all data simultaneously (the all-treatments model, Table 4) (a) S54, (b) S26, and (c) S13. period of elongation; these were successively longer. The remaining internodes were nearly equal in length until the final eight to 11 internodes, which were progressively shorter. One source of variability in internode length was that, although leaves were alternate, occasionally two successive leaves were almost opposite, resulting in particularly short and long internodes at that point.

Leaf unfolding rate of poinsettia has been shown to increase with increasing average temperature below $25^{\circ} \mathrm{C}$, and shoot elongation increases as DIF temperature increases (Berghage and Heins, 1991). Average temperature declined by over $1{ }^{\circ} \mathrm{C}$ during the experiment (Fig. 2c) with no significant trend in DIF temperature (Fig. 2d).

When the $f_{3-p h a s e}$ model was fit separately to each photoperiod treatment, the $R^{2}$ was over 0.99 in each case (Table 3 ). Ninety-five percent confidence intervals (data not shown) for parameter estimates of $\gamma, \Delta \mathrm{t}_{V P}$, and $\delta$ overlapped between all treatments, but $\alpha$ and $\beta$ confidence intervals did not. Initial cutting length was shorter for the S26 plants than for those of other treatments (Table 2), and the S26 treatment had the lowest estimate of $\alpha$. Plants in the S54 treatment initially elongated slowly, with the lowest estimate of $\beta$ and latest estimate of $t_{L}$. For the S13, S26, and S54 treatments, $t_{L}$ was estimated at 28, 24, and 33 days after transplant. From transplant to $t_{L}$, the model predicted 23,23 , and $29 \mathrm{~mm}$ of elongation (calculated as $f_{L A G}\left(t_{L}\right)-\alpha$ ) and plants unfolded 5, 5, and 8 leaves for the S13, S26, and S54 treatments, respectively. Data from the S26 treatment had the highest estimate of $\gamma ; 95 \%$ confidence intervals overlapped in the other two treatments, however. Estimates of $\Delta t_{V P}$, the length of the period between $t_{V}$ and $t_{P}$, ranged from 18 to 21 days. Estimates of $\delta$ had large coefficients of variation compared with other parameters (data not shown) and ranged from 18 to $34 \mathrm{~mm}$.

Predictions from the all-treatments model were generally within 95\% confidence intervals of observed plant height for all treatments, when differences in initial elongation rate (i.e., $\beta$ ) during the lag phase were incorporated directly. The observed initial length of each stem was used as an input variable to provide a value for $\alpha$. A separate $\beta$ parameter was incorporated for each treatment since the plants were somewhat different in initial vigor $\left(\beta_{13}, \beta_{26}\right.$, and $\beta_{54}$ for the S13, S26, and S54 treatments, respectively). Parameters $\mathrm{g}, \Delta t_{V P}$, and $\delta$ were assumed independent of treatment to highlight differences that occurred after the lag phase and were likely to be caused by timing of flower initiation. In the all-

Table 3. Parameter estimates \pm asymptotic standard error and computed variables for $f_{3 \text {-phase }}$ fit individually to each photoperiod treatment.

\begin{tabular}{|c|c|c|c|c|}
\hline & \multicolumn{3}{|c|}{ Photoperiod treatment } & \multirow[b]{2}{*}{ Units } \\
\hline & S13 & S26 & S54 & \\
\hline \multicolumn{5}{|c|}{ Parameter } \\
\hline$\alpha$ & $62.3 \pm 2.2$ & $37.9 \pm 2.4$ & $52.5 \pm 2.2$ & $\mathrm{~mm}$ \\
\hline$\beta$ & $0.114 \pm 0.006$ & $0.132 \pm 0.007$ & $0.102 \pm 0.004$ & per day \\
\hline$\gamma$ & $2.70 \pm 0.18$ & $3.19 \pm 0.10$ & $3.03 \pm 0.06$ & $\mathrm{~mm} \mathrm{~d}^{-1}$ \\
\hline$\Delta \mathrm{t}_{V P}$ & $17.7 \pm 4.2$ & $19.1 \pm 3.1$ & $20.9 \pm 4.0$ & days \\
\hline$\delta$ & $17.8 \pm 11.6$ & $27.8 \pm 11.1$ & $34.2 \pm 15.9$ & $\mathrm{~mm}$ \\
\hline \multicolumn{5}{|c|}{ Variable calculated from best-fit estimate } \\
\hline$t_{L}$ & 28 & 24 & 33 & days \\
\hline$t_{P}$ & 56 & 69 & 98 & days \\
\hline$f_{L A G}\left(t_{L}\right)$ & 85 & 61 & 81 & $\mathrm{~mm}$ \\
\hline$f_{L I N}\left(t_{P}\right)$ & 162 & 203 & 278 & $\mathrm{~mm}$ \\
\hline$k$ & 0.152 & 0.115 & 0.089 & per day \\
\hline$H_{f}$ & 179 & 231 & 312 & $\mathrm{~mm}$ \\
\hline$R^{\frac{1}{2}}$ & 0.995 & 0.995 & 0.996 & \\
\hline
\end{tabular}


Table 4. Analysis of variance and parameter estimates from fitting the $f_{3-\text { phase }}$ model to all data simultaneously (the all-treatments model).

\begin{tabular}{|c|c|c|c|c|}
\hline \multicolumn{2}{|l|}{ Source } & df & Sum of squares & Mean square \\
\hline \multicolumn{2}{|l|}{ Regression } & 6 & 12785093 & 2130849 \\
\hline \multicolumn{2}{|l|}{ Residual } & 419 & 48461 & 116 \\
\hline \multicolumn{2}{|l|}{ Uncorrected total } & 425 & 12833554 & \\
\hline \multicolumn{2}{|l|}{ Corrected total } & 424 & 2847055 & 0 \\
\hline \multicolumn{2}{|l|}{ Parameter } & & Estimate $\pm \mathrm{ASE}^{\mathrm{z}}$ & Unit \\
\hline \multicolumn{2}{|l|}{$\overline{\beta_{13}}$} & & $0.108 \pm 0.002$ & per day \\
\hline & & $0.148 \pm 0.003$ & per day \\
\hline \multicolumn{2}{|l|}{$\beta_{54}$} & & $0.101 \pm 0.002$ & per day \\
\hline \multicolumn{2}{|l|}{$\gamma$} & & $3.17 \pm 0.04$ & $\mathrm{~mm} \cdot \mathrm{d}^{-1}$ \\
\hline \multicolumn{2}{|l|}{$\Delta t_{V P}$} & & $18.39 \pm 1.9$ & days \\
\hline \multicolumn{2}{|l|}{$\delta$} & & $23.0 \pm 6.7$ & $\mathrm{~mm}$ \\
\hline Factor calculated from best-fit estimate ${ }^{y}$ & S13 & S26 & S54 & Unit \\
\hline$\overline{t_{L}}$ & 31 & 21 & 34 & days \\
\hline$t_{P}^{L}$ & 57 & 70 & 96 & days \\
\hline$f_{L A G}\left(t_{L}\right)-\alpha$ & 28 & 20 & 30 & $\mathrm{~mm}$ \\
\hline$f_{L I N}\left(t_{P}\right)-\alpha$ & 109 & 176 & 225 & $\mathrm{~mm}$ \\
\hline$k$ & 0.138 & 0.138 & 0.138 & per day \\
\hline$H_{f}^{-\alpha}$ & 132 & 199 & 248 & $\mathrm{~mm}$ \\
\hline
\end{tabular}

${ }^{\mathrm{z}} \mathrm{ASE}=$ asymptotic standard error.

'In this all-treatments model, parameters were estimated by substituting actual transplant height for $\alpha$. Fifty-six, 32, and 51 mm (from Table 1) were added to the S13, S26, and S54 model estimates, respectively, to calculate the heights displayed in Fig. 4.

treatments model, $t_{P}$ was linked to observed $t_{V}$ using Eq [9]. Fitting this all-treatments model to the combined data set resulted in an $R^{2}$ of 0.994 (Table 4), which represented the data very well (Fig. 4). Height of plants in the $S 13$ treatment were, however, underpredicted between day 10 and 20 (Fig 4c). Standard errors for parameter estimates generally were smaller than when the model was fit individually to data from each photoperiod treatment. The estimates of $\beta_{13}$ and $\beta_{54}$ were similar and significantly lower than the estimate of $\beta_{26}$. As a result, timing of $t_{L}$ was estimated to occur later for the S13 and S54 treatments than the S26 treatments, with correspondingly more elongation between transplant and $t_{L}$. The coefficient of variation was highest for the estimate of $\delta$. The final height estimated by the model was within $10 \mathrm{~mm}$ of the actual final height for all treatments, with errors of 8,3 , and $-4 \mathrm{~mm}$ for the S13, S26, and S54 treatments, respectively.

Observed mean height of the plants in the 1992 validation experiment fell within the maximum and minimum range predicted using the all-treatments model (Fig. 5a), where $\beta$ was assigned values of 0.101 and $0.148 / \mathrm{d}$ from the estimates in Table 4 for the S54 and S26 treatments. Final observed height was 237 $\pm 9 \mathrm{~mm}$ for plants in the 1992 experiment, compared with a predicted range of 228 to $260 \mathrm{~mm}$. Plants in the 1993 validation experiment were initially more vigorous that those grown during both the calibration experiment and in 1992 (Fig. 5b), and plant height was near the upper predicted range throughout the growing period. Visible bud occurred $24.8 \pm 4.6$ days after $t_{S}$ in the 1993 experiment, which was not significantly different from the estimate of 24.1 days for $\Delta t_{s V}$. Final plant height in 1993 was $296 \pm 47$ $\mathrm{mm}$, compared with the predicted range of 259 to $291 \mathrm{~mm}$.

\section{Discussion}

In published research, mathematical functions have been combined in various ways to remove biases in the empirical fitting to data, particularly in situations in which different growth phases are hypothesized to occur over an organism's life cycle. Brody (1945) described two phases of growth, modeling the first phase with an exponential function and describing the second using a form of the Richards function (the monomolecular function). The model predicted a sudden jump in the growth rate at the transition between growth phases. Hunt and Evans (1980) divided growth data of maize (Zea mays L.) into phases that were fitted by cubic splines
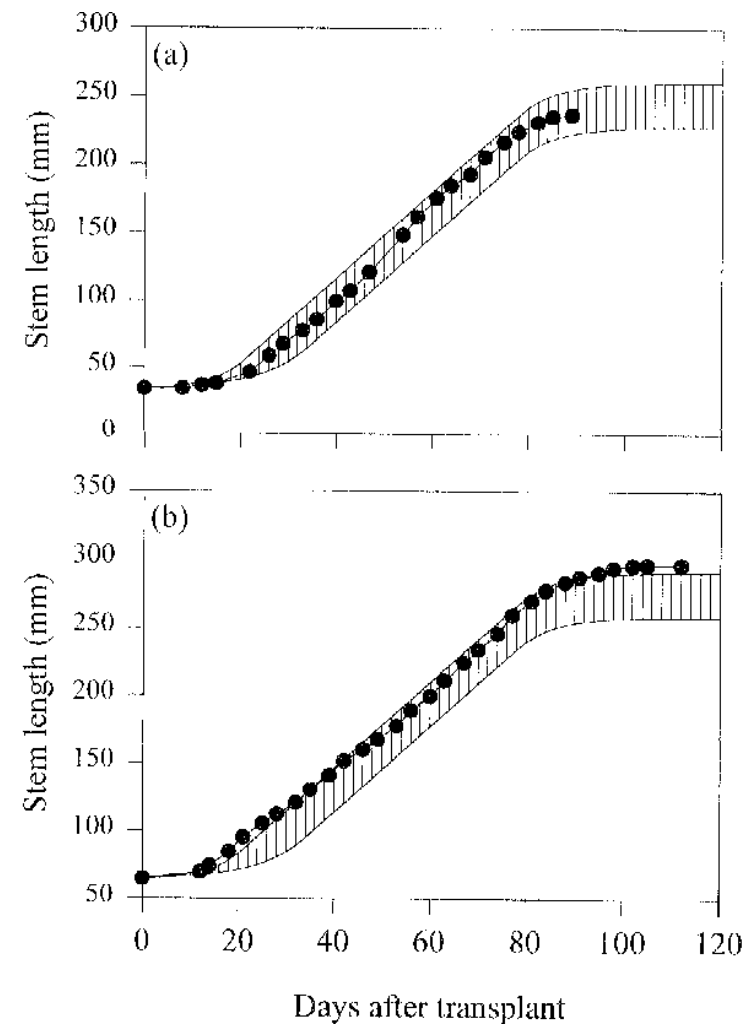

Fig. 5. Observed and predicted heights of plants grown in (a) 1992 and (b) 1993 validation experiments. Solid lines represent the predicted range using the alltreatments model with $\beta$ values between 0.101 and $0.148 / d$. (O) The observed mean of five plants. 
Fig. 6. Model predictions of plant heights for three short-day date $\left(t_{s}\right)$ assumptions (short days beginning 15,30 , and $45 \mathrm{~d}$ after transplant), a starting height of $50 \mathrm{~mm}$, and $\beta$ equal to $0.119 / \mathrm{d}$. Arrows represent timing of $t_{S}$, and $t_{P}$ occurs 42 days after $t_{S}$.

(polynomials) which agreed in position, slope, and rate of slope change, ensuring smooth transitions.

Another approach to modeling growth consists of summing two or more growth curves of some organism or population, which has been used by Genard and Bruchou (1993) to describe the growth of peach fruit. Berghage and Heins (1991) summed growth curves for poinsettia internodes to attain a stem-elongation model. Although techniques based on summation of parts can provide a close empirical fit to observed data, the resulting models are more complex and less suitable for dynamic simulation than a phasic model of the entire stem.

For modelling the stem elongation of single-stemmed poinsettia, the $f_{3-\text { phase }}$ function has several advantages over previous approaches. Parameters can be interpreted biologically, without the complexity of multiple polynomials used by Hunt and Evans (1980). The model provided a close fit to the observed plant heights and the required data collection is considerably simpler than the calibration and validation data necessary for Berghage and Heins' (1991) model. Equations were chosen that allow the model to be used for dynamic simulation, with smooth transitions between growth phases.

Using a model that explicitly separates the growth period into three phases yields information about the timing of developmental events. For poinsettia stem elongation, $t_{L}$ (the time of transition from the lag to linear phases) represents the time when maximum and constant absolute elongation rate begins, with uniform development and elongation of internodes over time. Time $t_{p}$, when the model changes from linear to plateau phases, represents the time when reproductive development under short days begins to affect stem elongation rate. The parameter $t_{p}$ was estimated to occur about 42 days $\left(\Delta t_{S V}+\Delta t_{V P}\right)$ after $t_{S} . H_{f}$ the asymptotic final height, computed as $f_{L I N}\left(t_{P}\right)+\delta$, increases the later $t_{P}$ occurs.

The $f_{3-p h a s e}$ function fit observed data closely and explained much of the variation, particularly during the linear and plateau phases. However, groups of treatment plants in the calibration and validation experiments varied in their initial elongation rate before $t_{L}$. The differences in initial transplant vigor were accounted for in the all-treatments model by separately estimating $\beta$ for data from each treatment. Because causes of variability in initial transplant vigor were not identified, the maximum and minimum $\beta$ values from the calibration experiment were used to predict a range of plant heights for model validation. Timing of $t_{L}$ was not correlated closely to a particular leaf number but consistently occurred when the plants had elongated at least $30 \mathrm{~mm}$. Plants in the $S 26$ treatment of the calibration experiment, and in the 1993 validation experiment were the most vigorous in terms of elongation rate during the lag phase. Differences in temperature and initial transplant length are insufficient to explain differences between initial elongation rate of treatments. Factors affecting variability between transplant batches, particularly during the lag phase, need to be addressed by further research so that the model can precisely predict plant height.

Assuming a starting length of $50 \mathrm{~mm}$ and $\beta=0.119$ per day (the average of all treatments), the model predicts a pattern (Fig. 6) in which varying $t_{s}$ affects final height because of the effect of $t_{S}$ on $t_{P}$. Varying $t_{S}$ in the $f_{3-\text { phase }}$ model leads to a family of curves that differs only in the timing of the plateau phase and resulting final height, which was hypothesized as the primary biological effect of $t_{s}$. This pattern is similar to the behavior of the internode-based model of Berghage and Heins (1991) in that there is an initial lag in elongation rate, an intermediate period of linear elongation during vegetative growth, and a finite potential elongation after $t_{s}$. The $f_{3-\text { phase }}$ model, however, is considerably simpler.

The multiphasic modeling approach could be modified for other horticultural applications. We chose to estimate $\alpha, \beta, \gamma, \Delta t_{V P}$, and $\delta$ by nonlinear regression and calculate other parameters. However, Eqs. [4] to [9] could be rearranged readily to alter which parameters were estimated or calculated. For example, $t_{L}$ could be estimated and $\gamma$ calculated. In addition, the number of phases could be altered (for example, where a lag phase does not occur or data are missing). Finally, the choice of equations within each stage could be changed. For example, if the initial size hypothetically affected subsequent growth rate, the lag phase could be reformulated as

$$
f_{\mathrm{LIN}}=\alpha e^{\beta t}
$$

Alternately, entirely different formulations could be used (e.g., a quadratic polynomial for $f_{L A G}$ ) as long as the conditions dictated by Eq. [2] are incorporated.

Dynamic simulation requires the use of rate equations (derivatives or differential equations). The $f_{3-p h a s e}$ model could be adapted to incorporate other variables; for example, average temperature or growth retardant applications. During the linear phase, linear elongation is assumed, based on uniform internode development and elongation rates over time. Increased elongation rate would be expected at higher temperatures, based on the leaf unfolding-rate response to average temperature. A leaf unfolding-rate model could be linked to $f_{3-p h a s e}$ so that growth and development could be tracked. An advantage of the incremental (phasic) nature of the model, with phase changes linked to observable events, is that $t_{L}$ and $t_{P}$ could be calibrated during simulation if actual height or $t_{V}$ were different from their predicted values. An example where it would be useful to calibrate the model based on observed phenology is when plants are grown under natural photoperiods (as in the 1992 validation experiment). Under natural photoperiods, $t_{S}$ cannot be identified precisely and actual visible bud date (substituted for $t_{V}$ ) can be used to calibrate the model and predict $t_{P}$. Factors that affect stem length (for example, growth retardant applications) could be incorporated by multiplying the first derivative by a perturbation function or scaler using the methodology described by Lieth and Reynolds (1986) and Larsen and Lieth (1993). The model, with or without such modifications, would require further validation with independent data before being used for simulation or applied commercially, particularly with different cultivars and greenhouse air temperatures.

The model is useful for graphical tracking, a technique in which a stem-elongation model is used to develop a target-height curve over time for use as a control chart (Karlsson and Heins, 1994). Actual height during the production season is plotted on the chart 
and compared against the target curve to show whether the height of a crop is within tolerances dictated by marketing and shipping factors.

The $f_{3-p h a s e}$ function is an empirical model designed for quantifying stem elongation of higher plants when it is desirable to model each phase of growth explicitly. Parameters had clear biological meaning and $t_{S}$ could be included as a variable. The $f_{3 \text {-phase }}$ function could be applied to other biological situations in which the identification of growth phases and their linkage to developmental events were important objectives.

\section{Literature Cited}

Berghage, R.D. and R.D. Heins. 1991. Quantification of temperature effects on stem elongation in poinsettia. J. Amer. Soc. Hort. Sci. 116:1418.

Brody, S. 1945. Bioenergetics and growth. Reinhold Publishing, New York.

Fisher, P.R. and R.D. Heins. 1995. A process-control approach to poinsettia height control. HortTechnology 5:57-63.

Genard, M. and C. Bruchou. 1993. A functional and exploratory approach to studying growth: The example of the peach fruit. J. Amer. Soc. Hort.
Sci. 118:317-323.

Hunt, R. and G.C. Evans. 1980. Classical data on the growth of maize: Curve fitting with statistical analysis. New Phytol. 86:155-180.

Karlsson, M.G. and R.D. Heins. 1994. A model of chrysanthemum stem elongation. J. Amer. Soc. Hort. Sci. 119:403-407.

Larsen, R.U. and J.H. Lieth. 1993. Shoot elongation retardation owing to daminozide in chrysanthemum: I. Modeling single applications. Scientia Hort. 53:109-125.

Larson, R.A. and R.W. Langhans. 1963. The influences of photoperiod on flower bud initiation in poinsettia (Euphorbia pulcherrima Willd.). Proc. Amer. Soc. Hort. Sci. 82:547-551.

Lieth, J.H. and P. Carpenter. 1990. Modeling stem elongation and leaf unfolding of Easter lily during greenhouse forcing. Scientia Hort. 44:149-162.

Lieth, J.H. and J.F. Reynolds. 1986. Plant growth analysis of discontinuous growth data: A modified Richards function. Scientia Hort. 28:301304.

Richards, F.J. 1959. A flexible growth function for empirical use. J. Expt. Bot. 10:290-300.

Richards, F.J. 1969. The quantitative analysis of growth, p. 3-76. In: F.C. Steward (ed.). Plant physiology: A treatise. Academic Press, New York. SAS Institute. 1988. SAS/STAT user's guide. release 6.03. SAS Institute, Cary, N.C. 